\title{
Spinal Cord Infarction in Clinical Neurology: A Review of Characteristics and Long-Term Prognosis in Comparison to Cerebral Infarction
}

\author{
Fredrik Romi $^{a} \quad$ Halvor Naess ${ }^{a, b}$ \\ ${ }^{a}$ Department of Neurology, Haukeland University Hospital, Bergen, and ${ }^{b}$ Centre for Age-Related Medicine, \\ Stavanger University Hospital, Stavanger, Norway
}

\section{Key Words}

Spinal cord · Stroke · Infarction · Prognosis · Neurology

\begin{abstract}
Spinal cord stroke is rare accounting for $0.3-1 \%$ of all strokes and is classified into upper (cervical) and lower (thoracolumbar) strokes. Patients present with severe deficits but later often show good functional improvement. On admission, younger age, male gender, hypertension, diabetes mellitus and elevated blood glucose indicate more severe spinal cord strokes. Treatment of these risk factors is essential in the acute phase. Biphasic spinal cord strokes are seen in onefifth of the patients. These present with acute or transient sensory spinal cord deficits often preceded by radiating pain between the shoulders, and should be considered and treated as imminent spinal cord strokes. Spinal cord infarction patients are younger and more often women compared to cerebral infarction patients. Traditional cerebrovascular risk factors are less relevant in spinal cord infarction. Spinal cord infarction patients are more likely to be discharged home and show better improvement after initial treatment compared to cerebral infarction patients. On long-term followup, spinal cord infarction patients have lower mortality and higher emotional well-being scores than cerebral infarction patients. Despite more chronic pain, the frequency of re-em-
\end{abstract}

ployment is higher among spinal cord infarction patients compared to cerebral infarction patients who are more often afflicted with cognitive function deficits.

(c) 2016 S. Karger AG, Basel

\section{Introduction}

Spinal cord stroke is a rare condition compared to cerebral stroke accounting for $0.3-1 \%$ of all strokes [1-4]. It is caused by acute disruption of the spinal cord blood supply resulting in ischemia, infarction and acute spinal cord dysfunction with related clinical neurological deficits linked to the blood supply territory of the affected anterior spinal artery and the 2 posterior spinal arteries $[1,5,6]$. The spinal arteries in turn receive their blood supply from different regional arteries: $\mathrm{C} 1-\mathrm{T} 3$ is supplied by the vertebral arteries, T3-T7 receives a branch from the intercostal arteries, T8 to the medullary conus is supplied by the Adamkiewicz artery and in some cases there is a medullary conus artery arising from the internal iliac artery [4].

Many papers are published on anterior spinal artery syndrome in relation to aortic aneurysm and other spinal and general surgical procedures [7-10]. The reality in neurology departments is different where most spinal 
cord strokes are spontaneous with no preceding surgery or aortic aneurysm $[1,2,4,11,12]$. There are very few papers published on spontaneous spinal cord infarction, and this review is based on available published material.

\section{Spinal Cord Stroke and Infarction in Neurology}

In a study on 32 spinal cord stroke patients admitted to a neurology department [4], 28 had infarctions, 3 had hemorrhages and 1 had arteriovenous fistula. Twenty-eight spinal cord strokes were spontaneous, 2 were secondary to aortic aneurysms and 2 postsurgical strokes. Thus, in a neurology department, the vast majority of the patients have spontaneous strokes with no preceding events. Spontaneous ischemic strokes are the most common spinal cord strokes in clinical neurology $[1,2,4,11,12]$, accounting for up to $86 \%$ of all spinal strokes, while spinal cord hemorrhages make only $9 \%$ of all cases [4]. These ratios are similar to what is found in cerebral strokes [13].

Biphasic ictus is seen in one-fifth of all spontaneous spinal cord infarctions $[1,2,4]$. It is therefore important to recognize these patients and start stroke treatment immediately after the first symptom presentation, usually acute or transient sensory spinal cord deficit symptoms preceded by radiating pain between the shoulders, in an effort to prevent the imminent second and more severe phase.

Hypertension, diabetes mellitus and elevated blood glucose on admission regardless of diabetes mellitus are risk factors associated with more severe spinal cord strokes. Cardiovascular risk factors are well-established etiological causes of cerebral stroke [14], but it is unknown to which extent they are able to inflict the spinal cord circulation. The mechanisms however are presumably similar to those in cerebral stroke [4]. In a study, atherosclerosis and cardioembolism were the cause of $14.2 \%$ of all spontaneous spinal cord strokes [11]. Treatment and prevention of these risk factors should be essential in acute spinal cord stroke management.

Younger patients and men usually present with more severe spinal cord strokes in the initial phase $[2,4]$. A week after ictus, however, men tend to improve more rapidly than women in terms of less severe disability scores in relation to their initial neurological deficits [4]. In cerebral stroke, cardiovascular risk factors are more common in men, while lifestyle-related cardiovascular risk factors are especially frequent among younger men [15, 16]. Cardiovascular prevention measures should also be considered in the prevention of spinal cord stroke especially in patients who suffer a spinal cord transient isch- emic attack or other transient spinal cord deficit symptoms where no other etiological cause is obvious.

The role of mechanical degenerative spinal column disease conditions in spinal cord stroke is debated with a couple of studies indicating some correlation [1, 12], while a large study showed no correlation at all [4].

Lower thoracolumbar spinal cord strokes are more common than upper cervical strokes. Although patients with upper strokes initially present with more severe neurological deficits, they improve more rapidly than patients with lower strokes [4]. This could be the result of larger initial deficit symptoms involving legs and arms and also more sensitive scores to severe deficits used in clinical practice. It is therefore important to recognize these patients since they usually show good improvement when receiving proper treatment. It is also important to prevent and treat possible complications during hospital stay, such as pneumonia, which is the most prevalent complication in these patients, to improve outcome [17].

\section{Spinal Cord Infarction Compared to Cerebral Infarction in Neurology}

In 2011, Naess and Romi [17] compared 28 spontaneous spinal cord infarction patients with 1,075 cerebral infarction patients. Spinal cord infarction patients were younger, more often women and less afflicted by hypertension and cardiac disease than cerebral infarction patients [14]. Hypertension, which is an important risk factor for cerebral infarction [18], seems to be of less importance in spinal cord infarction patients. Likewise, cardiac diseases, which are frequent causes of cerebral infarction, are less common among spinal cord infarction patients. However, there are no differences as to diabetes mellitus, peripheral artery disease, smoking and cholesterol. These are risk factors associated with atherosclerosis. Thus, a cautious interpretation of these findings is that spinal cord infarction is associated with atherosclerosis, but not with cardiac disease $[11,17]$.

In addition to cardiac disease and atherosclerosis, small vessel disease causing lacunar stroke is a frequent cause of cerebral infarction [19]. One may assume that small vessel disease is also a contributing cause in spinal cord infarction. However, except for low frequency of cardiac disease among lacunar stroke patients, the characteristics of lacunar stroke patients are more similar to non-lacunar stroke patients than to spinal cord infarction patients [17]. Therefore, small vessel disease may be a less relevant factor in spinal cord infarction.
Romi/Naess 
Severe neurological deficits on admission in spinal cord infarction are associated with high age, low systolic blood pressure on admission and elevated blood glucose [17]. Spinal cord infarction patients should be treated in the same way as cerebral infarction patients as to acute blood pressure and glucose management.

One week after symptom onset, functional scores are significantly worse among spinal cord infarction compared to cerebral infarction patients [17]. However, this difference seems to level out when patients are discharged from the ward $[1,17]$, and functional scores even become better among spinal cord infarction patients when adjusting for early functional level [17]. Spinal cord infarction patients are more likely to be discharged home, with an odds ratio of 5.5 compared to cerebral infarction patients after adjusting for early functional scores [17]. A possible explanation is that many cerebral infarction patients have cognitive dysfunction making discharge to home more difficult even though functional levels are comparable [20]. Another possibility is that spinal cord infarction patients have better functional progress after the first week in hospital.

\section{Long-Term Prognosis of Spinal Cord Infarction in Neurology}

There have been relatively few studies on long-term outcome after spinal cord infarction. One study included 115 patients of whom $60 \%$ had perioperative infarctions or infarctions caused by aortic aneurysm or dissection [7]. Another study included 54 patients with mixed spontaneous and non-spontaneous infarctions [21]. Only one study so far focused on long-term prognosis in spontaneous spinal cord infarction in 30 patients with a mean follow-up time of 7.1 years [22]. An important finding in this study was that long-term mortality was lower among spinal cord infarction patients (23\% after mean follow-up of 7.1 years) than among cerebral infarction patients (hazard ratio 0.2) after adjusting for age and functional scores in the acute phase. A possible explanation of this is that the frequencies of traditional risk factors, such as myocardial infarction, atrial fibrillation and hypertension, are lower in spinal cord infarction patients [17]. Long-term mortality among cerebral infarction patients is associated with these traditional risk factors $[23,24]$. Another study, which included both spontaneous and non-spontaneous spinal cord infarctions, has also reported low long-term mortality (9\% after a mean follow-up of 4.5 years) [21]. Patients with predominantly non-spontaneous spinal cord infarction related to surgery or aortic aneurysm and dissection have higher

Spinal Cord Infarction in Clinical Neurology long-term mortality (23\% after 3 years follow-up) [7]. Long-term mortality in spinal cord infarction patients is associated with higher age, severity of deficits in the acute phase and peripheral vascular disease [7, 22].

Many spinal cord infarction patients experience significant improvement with time. Up to half of the patients who were unable to walk 1 week after spinal cord infarction onset are able to walk on follow-up [7,22]. Of all spinal cord infarction patients, two-thirds are able to walk on follow-up [21, 22]. Long-term prognosis as to functional state is better than previously reported [2].

In the long-term, almost all surviving patients $<60$ years at onset of their spinal cord infarction return to their jobs. By contrast, re-employment is lower among patients $<60$ years at the onset of their cerebral infarction even when their functional scores are better than those of spinal cord infarction patients [22]. Cerebral infarction patients often have cognitive deficits, whereas cognitive deficits are rare among spinal cord infarction patients and probably do not differ from those in other hospitalized patients with equally serious conditions. The difference in re-employment probably reflects this dissimilarity in cognitive functioning. Normal cognitive functioning is probably more important than normal physical functioning in today's labor market. This dissimilarity cannot be attributed to any other factors such as fatigue or depression since the occurrence of these factors is similar among these 2 patient groups and both of them have higher fatigue scores than healthy individuals. The emotional well-being scores in spinal cord infarction patients may play a decisive role in this aspect since these scores are higher than in cerebral infarction patients and similar to those found in healthy individuals $[22,25]$.

Up to $79 \%$ of spinal cord infarction patients report chronic pain on follow-up, and this is more frequent than in cerebral infarction patients where less than half report pain on follow-up [7, 22]. Pain is not associated with functional state in spinal cord infarction patients. By contrast, pain has been reported to be associated with functional state in cerebral infarction patients [26]. Central pain is rare in cerebral infarction patients [27], but possibly more frequent in spinal cord infarction patients.

\section{Conclusions}

A classification of spontaneous spinal cord infarction into upper (cervical) and lower (thoracolumbar) correlates to severity. Younger age, male gender, hypertension, diabetes mellitus and elevated blood glucose indicate more severe spinal cord strokes on admission. Treatment 
of these risk factors is essential in the acute phase. Biphasic spinal cord strokes are seen in one-fifth of the patients and usually present with acute or transient sensory spinal cord deficit. These symptoms should be considered and treated as imminent spinal cord strokes.

Spinal cord infarction patients are younger and more often women compared to cerebral infarction patients. Traditional cerebrovascular risk factors are less relevant in spinal cord infarction. Spinal cord infarction patients are more likely to be discharged home and show better improvement after initial treatment compared to cerebral infarction patients.
Spinal cord infarction patients have lower mortality and higher emotional well-being scores than cerebral infarction patients on long-term follow-up. Despite more chronic pain, the frequency of re-employment is higher among spinal cord infarction patients compared to cerebral infarction patients who are more often afflicted with cognitive function deficits.

\section{Disclosure Statement}

The authors have no conflicts of interest to disclose.

\section{References}

1 Novy J, Carruzzo A, Maeder P, Bogousslavsky $\mathrm{J}$ : Spinal cord ischemia: clinical and imaging patterns, pathogenesis, and outcomes in 27 patients. Arch Neurol 2006;63:1113-1120.

2 Cheng MY, Lyu RK, Chang YJ, Chen RS, Huang CC, Wu T, Lee TH, Lu CS, Ro LS: Spinal cord infarction in Chinese patients. Clinical features, risk factors, imaging and prognosis. Cerebrovasc Dis 2008;26:502-508.

3 Sandson TA, Friedman JH: Spinal cord infarction. Report of 8 cases and review of the literature. Medicine (Baltimore) 1989;68:282-292.

4 Romi F, Naess H: Characteristics of spinal cord stroke in clinical neurology. Eur Neurol 2011;66:305-309.

5 Shamji MF, Maziak DE, Shamji FM, Ginsberg RJ, Pon R: Circulation of the spinal cord: an important consideration for thoracic surgeons. Ann Thorac Surg 2003;76:315-321.

6 Sliwa JA, Maclean IC: Ischemic myelopathy: a review of spinal vasculature and related clinical syndromes. Arch Phys Med Rehabil 1992; 73:365-372.

7 Robertson CE, Brown RD Jr, Wijdicks EF, Rabinstein AA: Recovery after spinal cord infarcts: long-term outcome in 115 patients. Neurology 2012;78:114-121.

8 Fehrenbacher JW, Siderys H, Terry C, Kuhn J, Corvera JS: Early and late results of descending thoracic and thoracoabdominal aortic aneurysm open repair with deep hypothermia and circulatory arrest. J Thorac Cardiovasc Surg 2010;140(6 suppl):S154-S160; discussion S185-S190.

9 Bley TA, Duffek CC, François CJ, Schiebler ML, Acher CW, Mell M, Grist TM, Reeder SB: Presurgical localization of the artery of Adamkiewicz with time-resolved 3.0-T MR angiography. Radiology 2010;255:873-881.

10 Charles YP, Barbe B, Beaujeux R, Boujan F, Steib JP: Relevance of the anatomical location of the Adamkiewicz artery in spine surgery. Surg Radiol Anat 2011;33:3-9.
11 Ghandehari K, Gerami Sarabi MR, Maarufi P: Clinical evaluation of patients with spinal cord infarction in Mashhad, Iran. Stroke Res Treat 2010;2010:942417.

12 Kumral E, Polat F, Güllüoglu H, Uzunköprü C, Tuncel R, Alpaydin S: Spinal ischaemic stroke: clinical and radiological findings and shortterm outcome. Eur J Neurol 2011;18:232-239.

13 Thomassen L, Waje-Andreassen U, Næss H, Brøgger J: [Treatment of cerebrovascular disease in a comprehensive stroke unit]. Tidsskr Nor Laegeforen 2011;131:819-823.

14 Jørgensen HS, Nakayama H, Raaschou HO, Olsen TS: Effect of blood pressure and diabetes on stroke in progression. Lancet 1994;344: 156-159.

15 Andersen KK, Andersen ZJ, Olsen TS: Ageand gender-specific prevalence of cardiovascular risk factors in 40,102 patients with firstever ischemic stroke: a nationwide Danish study. Stroke 2010;41:2768-2774.

16 O'Donnell MJ, Xavier D, Liu L, Zhang H, Chin SL, Rao-Melacini P, Rangarajan S, Islam S, Pais P, McQueen MJ, Mondo C, Damasceno A, Lopez-Jaramillo P, Hankey GJ, Dans AL, Yusoff K, Truelsen T, Diener HC, Sacco RL, Ryglewicz D, Czlonkowska A, Weimar C, Wang X, Yusuf S; INTERSTROKE Investigators: Risk factors for ischaemic and intracerebral haemorrhagic stroke in 22 countries (the INTERSTROKE study): a case-control study. Lancet 2010;376:112-123.

17 Naess H, Romi F: Comparing patients with spinal cord infarction and cerebral infarction: clinical characteristics, and short-term outcome. Vasc Health Risk Manag 2011;7:497502.

18 Bejot Y, Caillier M, Ben Salem D, Couvreur G, Rouaud O, Osseby GV, Durier J, Marie C, Moreau T, Giroud M: Ischaemic stroke subtypes and associated risk factors: a French population based study. J Neurol Neurosurg Psychiatry 2008;79:1344-1348.
19 Kolominsky-Rabas PL, Weber M, Gefeller O, Neundoerfer B, Heuschmann PU: Epidemiology of ischemic stroke subtypes according to TOAST criteria: incidence, recurrence, and long-term survival in ischemic stroke subtypes: a population-based study. Stroke 2001; 32:2735-2740.

20 Tatemichi TK, Desmond DW, Stern Y, Paik M, Sano M, Bagiella E: Cognitive impairment after stroke: frequency, patterns, and relationship to functional abilities. J Neurol Neurosurg Psychiatry 1994;57:202-207.

21 Nedeltchev K, Loher TJ, Stepper F, Arnold M, Schroth G, Mattle HP, Sturzenegger M: Longterm outcome of acute spinal cord ischemia syndrome. Stroke 2004;35:560-565.

22 Hanson SR, Romi F, Rekand T, Naess H: Long-term outcome after spinal cord infarctions. Acta Neurol Scand 2015;131:253-257.

23 Putaala J, Curtze S, Hiltunen S, Tolppanen H, Kaste M, Tatlisumak T: Causes of death and predictors of 5-year mortality in young adults after first-ever ischemic stroke: the Helsinki young stroke registry. Stroke 2009;40:26982703.

24 Gjerde G, Naess H: Risk factor burden predicts long-term mortality after cerebral infarction. Acta Neurol Scand 2014;129:173177.

25 Naess H, Nyland HI, Thomassen L, Aarseth J, Myhr KM: Fatigue at long-term follow-up in young adults with cerebral infarction. Cerebrovasc Dis 2005;20:245-250.

26 Naess H, Lunde L, Brogger J, Waje-Andreassen U: Post-stroke pain on long-term followup: the Bergen stroke study. J Neurol 2010; 257:1446-1452.

27 Jönsson AC, Lindgren I, Hallström B, Norrving B, Lindgren A: Prevalence and intensity of pain after stroke: a population based study focusing on patients' perspectives. J Neurol Neurosurg Psychiatry 2006;77:590-595. 